\title{
Prolongation of Lumbar Facet Joint Nerve Block Duration with 10\% Lidocaine Neurolysis: A Retrospective Cohort Study
}

\author{
David D. Kim, MD, Daanish Khaja, MD, and Nabil Sibai, MD
}

Background: Neural blockade of the facet medial branch/L5 dorsal rami with local anesthetic with or without corticosteroid has been used to both diagnose and treat low back pain. Higher concentration lidocaine has been shown to be neurolytic in multiple in vivo, in vitro, and some clinical studies. This may make $10 \%$ lidocaine a possible neurolytic agent to prolong pain relief from facet blocks.

Objective: Compare neurolytic effects of $10 \%$ lidocaine to prolong pain relief compared to bupivacaine/methylprednisolone $(\mathrm{BM})$ in facet medial branch/L5 dorsal rami blocks (MBB).

Methods: Retrospective review of 77 patients who received a $10 \%$ lidocaine MBB from after short term relief from MBB with BM. Comparison was made in visual analog scale (VAS) and duration of relief using Wilcoxon signed rank matched pairs test.

Results: There was no significant difference between baseline median VAS prior to MBB with $\mathrm{BM}$ and $10 \%$ lidocaine and median days VAS recorded post each MBB $((P=0.477)$. Median VAS immediately after BM MBB $(17.5 \mathrm{~mm})$ was not significantly different than after $10 \%$ Lidocaine MBB $)$ of $18 \mathrm{~mm}(P=0.341)$. Median duration of relief with $10 \%$ lidocaine was greater at 14 days versus BM at 3.5 days $(P=0.001)$. There was no significant correlation between the volume of $10 \%$ lidocaine at each level and performance measures: $\%$ change VAS post lidocaine MBB ( $P=$ $0.529)$, duration lidocaine MBB $(P=935)$, VAS pre-RFTC $(P=0.683)$.

Limitation: Retrospective, small study.

Conclusion: Ten percent lidocaine was moderately effective neurolytic agent with longer duration than BM.

Key words: Lidocaine, facet joint, neurolysis, low back pain
Low back pain is a common ailment with one month prevalence of $23.2 \%$ and can become chronic in $65 \%$ of those patients at one year $(1,2)$. The facet joints have been recognized as a common source of low back pain (3-7). Even with the advent of diagnostic imaging, delineating the source of pain has been shown to be difficult given the high rates of false-positive findings seen in plain-view radiography (X-rays), computed

From : Henry Ford Hospital, Detroit, MI

Author for correspondence: David D. Kim, MD

Address: Henry Ford Hospital I-3 Pain Clinic,

2799 W. Grand Blvd, Detroit, MI 48202

E-mail: dkim1@hfhs.org tomography (CT), magnetic resonance imaging (MRI), bone scans, and single photon computed tomography (SPECT) imaging (8-11). Physical examination has not proven to be a reliable tool for diagnosis either (12). Neural blockade of the medial branches of the dorsal rami innervating the facet joints has been used for diagnostic purposes in multiple studies (3-5,13-16). Some studies have reported the therapeutic value of facet medial branch/L5 dorsal ramus block (MBB) with pain relief beyond the duration expected from local anesthetic with or without corticosteroids (3-5,13-16). There has been a general consensus that 2 diagnostic MBB should be performed to decrease the rate of false positives (3-5). Those patients with short-term relief with diagnostic blockade typically proceeded to radiofrequency thermocoagulation (RFTC) to achieve long-term pain relief although a significant percentage 
of patients may not respond to ablation therapy despite positive response to diagnostic blockade (17-20). Typical local anesthetics used for MBB include lidocaine and bupivacaine with mean duration of action lasting 2 to 8 hours, respectively. The addition of corticosteroid to the injectate has the theoretical advantage of inhibition of $\mathrm{C}$-fiber transmission and therefore may prolong blockade, but not without the typical side effects of corticosteroids (21). Lidocaine has been shown to be neurotoxic in multiple in vitro (cell) and in vivo (animal) studies (22-34). Ready et al (25) reported persistent neurological deficit and major histological changes starting at $8 \%$ concentration when injected intrathecally in rabbits, but not below this concentration. Literature on clinical use of higher concentration lidocaine for chronic pain was limited to a few small case series. Choi et al (35) reported 3 cases of patients who had several months of pain relief with peripheral nerve blocks using $5 \%$ lidocaine with $7.5 \%$ dextrose. Their study was problematic given the concentration used was less than the $8 \%$ concentration seen in the animal study by Ready et al (25). In humans, lower concentration $5 \%$ lidocaine did not show consistent neurolytic effect in the context of transient neurologic symptoms (TNS) in spinal anesthesia (36-37). The author presented histologic evidence of the neurolytic effect of perineural injections of $10 \%$ lidocaine in a canine sciatic nerve with no accompanying gross changes in the surrounding muscle and connective tissue (38). The same author demonstrated prolonged headache relief with blockades using 10\% lidocaine versus $0.5 \%$ bupivacaine/methylprednisolone (BM) of the greater occipital nerve (39). Han et al (40) also demonstrated the neurolytic effects of $10 \%$ lidocaine with pain relief of up to 172 days after blockade of the trigeminal nerve. Lee reported an abstract case series of 25 patients with a variety of neuropathic pain, including postherpetic neuralgia, trigeminal neuralgia, and post-operative neuralgia, receiving pain relief for 4 weeks to 6 months with $10 \%$ lidocaine (41). Our present study tests the hypothesis that lidocaine greater than $8 \%$ concentration can be an alternative neurolytic agent in the prolongation of low back pain relief for short term responders to MBB performed with standard BM blocking agent in a retrospective study.

\section{METHODS}

After Institutional Review Board (IRB) at Henry Ford Hospital (Detroit, MI) approval, a retrospective chart review was performed on all patients at Henry Ford Hospital Pain Clinic, Columbus Center (Novi, MI) who received $10 \%$ lidocaine MBB from January 2015 to December 2016. It had been a general practice in our pain clinic to perform lumbar MBB with $10 \%$ lidocaine if patient had relief of at least 8 hours of $\geq 50 \%$ decrease in visual analog score (VAS) with the first MBB using BM. All patients were at least 18 years old with greater than 3 months of low back that did not radiate below the knee and positive MRI or CT imaging for facet arthropathy without evidence of significant stenosis. Physical exam findings were positive for pain reproduction with extension/lateral bending, negative for any neurologic deficits, and negative straight leg raise sign. The levels to be injected were determined after correlation with imaging and physical exam findings. The MBB were performed after obtaining informed consent and using standard technique: fluoroscopic guidance using a 22or 25-gauge Quincke spinal needle, which was guided to the junction of the superior articular process and its pedicle/ transverse process. After confirmation of needle position on anterior/posterior (AP) and lateral view, 0.1 $\mathrm{mL}$ of isovue m-300 or gadolinium contrast dye was injected to confirm correct position. After which, each site was injected with $1 \mathrm{~mL}$ of a solution containing 9 $\mathrm{mL}$ of preservative free $0.5 \%$ bupivacaine and $40 \mathrm{mg}$ methylprednisolone (4.5 mg bupivacaine/4mg methylprednisolone/level). Each patient had an intravenous (IV) line placed prior to the procedure and was given 1-2 mg of midazolam for sedation. The American Society of Anesthesiologists (ASA) standard monitoring for monitored anesthesia care was applied: pulse oximetry, heart rate, electrocardiogram (ECG), and carbon dioxide monitoring. The patients were then given pain diaries in order to monitor and record their pain every 2 hours for the first day, then once a day for the next 5 days. They would return for the second MBB at 1-2 months from the initial procedure. If they received at least 8 hours of pain relief $\geq 50 \%$ decrease in VAS, but less than 1 month, the same procedure was performed with $10 \%$ lidocaine. Of note, the patients were given the same amount of IV sedation for both BM and 10\% lidocaine blocks to reduce any confounding factors. The preservative free $10 \%$ lidocaine was compounded by Health Dimensions Compounding Pharmacy (Farmington, MI). At the time of the second MBB, each patient was asked about the duration of pain relief $\geq 50 \%$ and their VAS at the moment of follow-up. The maximum total volume of $10 \%$ lidocaine that could be injected for the procedure was based on $80 \%$ of the maximum dose $(4 \mathrm{mg} / \mathrm{kg}$ ) 
Prolongation of Lumbar Facet Joint Nerve Block Duration

with the total volume divided evenly among the levels of MBB performed. The volume of $10 \%$ lidocaine used at each level, however, was limited to not exceed $1 \mathrm{~mL}$ at each level to decrease the chance of spreading to surrounding structures. The patients were asked to notify the performing physician if they noted any signs of local anesthetic toxicity. The patients were given pain diaries as before and returned for follow-up in 1-2 months for possible RFTC. As before, patients were asked about the duration of pain relief $\geq 50 \%$ and their VAS at the moment of follow-up. Demographic data including age, gender, number of levels performed, whether unilateral or bilateral, and volume of lidocaine at each level were recorded. Comparison were made between (VAS preBM MBB) versus ( VAS pre-lidocaine MBB ), (VAS post-BM MBB) versus (VAS postlidocaine $\mathrm{MBB})$, (\% change VAS post-BM $M B B$ ) versus (\% change VAS post-lidocaine $M B B$ ), (duration BM MBB) versus (duration lidocaine MBB ), (VAS pre-BM MBB) versus (VAS pre-RFTC ), (days post- BM MBB that lidocaine performed) versus (days post lidocaine RFTC performed). Volume of lidocaine used at each level was correlated with (\% change VAS post-lidocaine MBB), (duration lidocaine MBB), and (VAS post-lidocaine MBB). Matched-pairs signed-rank Wilcoxon test was used to assess the difference between the variables considered. The data was not normally distributed, which necessitated the use of a nonparametric test as well as nonparametric Spearman correction in the analysis.

Table 2. Comparison of VAS, change in VAS, and duration of pain relief after MBB with BM versus $10 \%$ lidocaine.

\begin{tabular}{|l|c|c|c|}
\hline & $\begin{array}{c}\text { Median VAS }(\mathbf{m m}) \\
(\mathbf{m e a n} / \mathbf{S D})\end{array}$ & $\begin{array}{c}\text { Median Change VAS }(\%) \\
(\mathbf{m e a n} / \mathrm{SD})\end{array}$ & $\begin{array}{c}\text { Median Duration of Relief } \\
\text { (Days) }(\mathbf{m e a n} / \mathbf{S D})\end{array}$ \\
\hline Pre-BM MBB & $70(67.3 / \mathrm{SD}=17)$ & & \\
\hline Pre-Lidocaine MBB & $70(66 / \mathrm{SD}=16.8)$ & & \\
\hline$P$-Value & 0.477 & & $3.5(10.7 / \mathrm{SD}=16.7)$ \\
\hline Post-BM MBB & $17.5(18.8 / \mathrm{SD}=12.4)$ & $-77.1(-72.5 / \mathrm{SD}=16.2)$ & $14(28.9 / \mathrm{SD}=40.1)$ \\
\hline Post-Lidocaine MBB & $18(21.6 / \mathrm{SD}=17.3)$ & $-75(-68.3 / \mathrm{SD}=21.6)$ & 0.001 \\
\hline$P$-Value & 0.341 & 0.029 & \\
\hline
\end{tabular}

\section{RESULTS}

During the 2-year time period of the study, a total of 352 patient had MBB performed. Of those, 188 did not have $50 \%$ relief, and 59 were lost to follow-up. Twenty-eight still had $\geq 50 \%$ relief on 1-2 months follow-up, so they did not receive confirmatory second MBBs. A total of 77 patients had $<1-2$ months of relief therefore, they had $10 \%$ lidocaine MBB performed. Of the patients in the study, $56 \%$ were men, $44 \%$ women, and the median age was 64 (Table 1). $57.1 \%$ had unilateral blocks with median number of 3 levels performed and the median volume of $10 \%$ lidocaine used per level was $0.75 \mathrm{~mL}$ (Table 1). Median (VAS pre- BM MBB) was $70 \mathrm{~mm}$ (mean: 67.3/SD: 17) and median (VAS pre-lidocaine MBB) was $70 \mathrm{~mm}$ (mean: 66/SD: 16.8) with no significant difference between the baseline pain before each injection $(P=0.477)$ (Table 2$)$. The median (days post-BM MBB lidocaine performed) of 30 (mean: 41.8/SD: 35.4) was marginally shorter than median (days post lidocaine RFTC performed), which was 38 (mean 59.8/SD: 60.2) ( $P=0.008$ ). Median (VAS post BM MBB) was 17.5 (mean 18.8 /SD: $12.4 \mathrm{~mm}$ ), which was not significantly different than median (VAS post Lidocaine MBB), which was 18 (mean: $21.6 / S D: 17.3 \mathrm{~mm})(P=0.341)$ (Table 2). Both groups had reported a decrease in VAS post blockade on follow-up with median (\% change VAS post-BM MBB) of $-77.1 \%$ (mean: $-72.5 / \mathrm{SD}: 16.2$ ) versus (\% change VAS post-lidocaine MBB) of $-75 \%$ (mean: 68.3/SD: 21.6$)$ with no significant difference between both groups $(P=-0.029)$ (Table $2)$. There was, however, significant greater mean duration of pain relief $\geq 50 \%$ reported by patients who received lidocaine MBB versus BM MBB. Median duration of relief with lidocaine was 14 days (mean: 28.9/SD: 40.1) versus duration of relief with

Table 1. Patient demographics.

\begin{tabular}{|c|c|c|c|c|c|c|}
\hline \multicolumn{2}{|c|}{ Gender } & Median & \multicolumn{2}{|c|}{ Location } & $\begin{array}{l}\text { Median } \\
\text { Number }\end{array}$ & $\begin{array}{l}\text { Median } \\
\text { Volume }\end{array}$ \\
\hline Men & Women & & Unilateral & Bilateral & & \\
\hline $\begin{array}{c}56 \% \\
(\mathrm{n}=43)\end{array}$ & $\begin{array}{c}44 \% \\
(n=34)\end{array}$ & 64 & $\begin{array}{l}57.1 \% \\
(\mathrm{n}=44)\end{array}$ & $\begin{array}{c}42.9 \% \\
(\mathrm{n}=33)\end{array}$ & 3 & 0.75 \\
\hline
\end{tabular}


BM MBB was 3.5 days (mean 10.7/SD: 16.7$)(P=$ 0.001 ) (Table 2). There was no significant correlation between the volume of $10 \%$ lidocaine at each level and performance measures of blockade: \% change VAS post lidocaine MBB $(P=0.529)$, duration lidocaine MBB $(P=0.935)$, VAS pre-RFTC $(P=0.683)$.

\section{DISCUSSION}

\section{Duration Bupivacaine with or without Corticoste- roid vs. $10 \%$ Lidocaine}

Based on the limited literature, the duration of response to MBB appeared in some cases to be longer than expected with the procedure having both diagnostic and therapeutic effect. Manchikanti et al (15) published a randomized trial of patients who received either bupivacaine, bupivacaine with Sarapin (High Chemical Company, Levittown, PA), or bupivacaine with corticosteroid. The average duration was prolonged beyond what would be expected from local anesthetic /corticosteroid effect. The authors reported durations of 12.5 weeks in the bupivacaine nonsteroid group versus 14.8 weeks in the steroid group. Rocha et al (42) performed saline MBB and those who had no relief immediately underwent repeat block with $2 \%$ lidocaine. Of the 54 patients who responded to lidocaine and not saline with > 50\% decrease in VAS, $36(67 \%)$ maintained pain improvement after 3 months. Pampati et al (16) performed MBB first with 1\% lidocaine and the second with $0.25 \%$ bupivacaine. No significant differences were noted with mean pain relief of 3.6 to 3.8 weeks with the first diagnostic block with lidocaine and of 5.9 to 6.9 weeks with confirmatory bupivacaine block. In the present study, the average duration of relief with bupivacaine was still longer than expected for just local anesthetic effect of 8 hours with median duration of 3.5 days (mean: 10.5). The mechanism of prolonged relief with local anesthetics had been speculated in multiple studies, including suppression of nociceptive discharge, axonal transport inhibition, sympathetic blockage, desensitization, and anti-inflammatory effects (43-48). This can also be seen in fact that the absolute VAS on follow-up after $10 \%$ lidocaine was significantly less than baseline VAS even after 1 month. The literature was mixed on the additive effect of corticosteroids as mentioned in the previously mentioned study by Manchikanti et al (13). Besides the obvious anti-inflammatory action, corticosteroids have been shown to directly inhibit Cfibers and $\operatorname{GABA}(21,49)$. The prospect of false posi- tives has always challenged the veracity of diagnostic nerve blocks and is always a question mark especially in those who undergo a single block. Prevalence and false positivity rates with dual injections using $\geq 50 \%$ decrease in VAS has described in multiple studies with prevalence reported to be $15-61 \%$ and with false positive rates of $17-66 \%(15,50-54)$. In our study, $10 \%$ lidocaine MBB used had the disadvantage of being the second MBB, but the present study had a low false positive rate of only $5.1 \%(n=4)$ received $<50 \%$ relief with $10 \%$ lidocaine. One limitation to this study is the nonstandard use of IV versed for sedation for both MBB performed with $10 \%$ lidocaine and BM. Manchikanti studied the effect of sedation with fentanyl or versed on diagnostic accuracy of MBB and found minimal effect when $80 \%$ relief was used as cut off for diagnosis. The effect of sedation became more significant when $50 \%$ reduction was used as diagnostic criteria as was used in the present study, however, both BM and $10 \%$ lidocaine groups were given sedation, which may decrease the effect sedation as a confounding factor (55-56).

\section{Lidocaine as a Neurolytic Agent}

Most animal studies used concentrations of $5 \%$ or less to study neurotoxicity since this is the most common clinically used concentration (23-34). Previous studies used direct intraneural injection, intrathecal injection, desheathed nerves, and cell cultures (23-34). Only Kalichman et al (23) injected lidocaine perineurally by piercing the connective tissue separating the neural tissue from overlying muscle rat sciatic nerves. They reported endoneurial edema, collapsed myelin sheaths, and axonal degeneration. However, this study used 3\% lidocaine, a lower concentration than seen in previous studies. Although animal models had shown evidence of neurotoxicity at clinically used concentrations of $5 \%$ or less, evidence of neurotoxicity in humans at these concentrations appeared to be much less than expected and inconsistent. This had been well documented in the use intrathecal lidocaine for spinal anesthesia and the phenomenon of TNS. Keld et al (37) compared $5 \%$ lidocaine versus $0.5 \%$ bupivacaine and found lidocaine caused TNS in only $26 \%$ of patients. The reason only a small percentage of patients have transient neurologic deficits may be explained by the study by Ready et al (25) who reported prolonged neurologic deficit and profound histologic changes after intrathecal injection in rabbits 
Prolongation of Lumbar Facet Joint Nerve Block Duration

occurred only at lidocaine concentrations $\geq 8 \%$ which was compatible with the previously mentioned clinical experience in humans. Ten percent lidocaine in our study allowed local concentrations $\geq 8 \%$ despite the requirement to inject contrast beforehand to exclude vascular and neural uptake.

\section{Duration of $10 \%$ Lidocaine vs. RFTC}

RFTC has been performed to prolong pain relief after positive response from facet MBB. Civelek et al (57) reported pain relief in $90 \%$ of RFTC patients and $69 \%$ relief with facet MBB at 12 months. Dobrogowski et al (58) reported $60 \%$ RFTC patients with pain relief at 6 months. Son et al (59) reported a mean duration of 10.9 months of $>50 \%$ pain relief in $85 \%$ of patient. Previous clinical studies with higher concentration lidocaine were limited but did note prolongation of relief close to relief with RFTC although a direct comparison had not been performed. Choi et al (35) reported 3 cases of patients who had months of relief with peripheral nerve blocks of using $5 \%$ lidocaine with 7.5 dextrose. A previous study by Kim et al (38) demonstrated prolonged headache pain relief with greater occipital nerve blockade using $10 \%$ lidocaine versus BM (148.05 days versus 6.33 day). Han et al (40) also demonstrated the clinical neurolytic effects of $10 \%$ lidocaine with pain relief 3-172 days after blockade of the trigeminal nerve. Lee (41) reported a duration of relief of 4 weeks to 6 months. The duration of $\geq 50 \%$ pain relief with $10 \%$ lidocaine, although significantly longer than with $\mathrm{BM}$, was less than the relief reported by previously mentioned studies on RFTC or previous $10 \%$ lidocaine studies. However, the absolute level of pain (VAS) after $10 \%$ lidocaine prior to RFTC was significantly less than baseline pain level prior to any treatment indicating continued prolongation of relief with $10 \%$ lidocaine although below the $\geq 50 \%$ pain reduction threshold. One explanation could be the anatomy and the difference in needle placement in RFTC versus MBB. The medial branch is covered by the mamillo-accessory ligament which runs from the mammillary process to the accessory process of vertebrae, which encloses the medial arch of the dorsal rami in an osseofibrous tunnel. RFTC is usually performed with the electrode slipping anteriorly allowing direct contact with the medial branch. The MBB is performed short of this target relying on local spread of local anesthetic. In the animal study by Kim et al (39), neurolysis was noted on direct perineural contact to the neural tissue. This direct contact may be easier in the blockade of other peripheral nerves blocked in the previously mentioned $10 \%$ lidocaine studies given the lesser amount of surrounding soft tissue and larger volumes of $10 \%$ lidocaine used. There is no data comparing lesion size between RFTC and MBB. Data concerning lesion size from neurolytics for MBB is limited to one study by Dreyfuss et al (60) who tracked contrast spread on fluoroscopy and CT scan after MBB and found consistent spread to the medial branch but the size of the spread was not quantified. The size of lesions from RFTC has been well studied by Cosman et al (61) and Provenzano et al (62). Cosman reported lesion size was dependent on tip gauge, tip length, temperature and duration. A typical 20 -gauge, RTFC probe with $10 \mathrm{~mm}$ active tip was found to produce lesion $6.2 \mathrm{~mm}$ in width and 12 $\mathrm{mm}$ in length. Provenzano reported that lesion size can be increased by injecting lidocaine or saline.

\section{Complications of $10 \%$ Lidocaine}

Besides the known cardiac and central nervous system toxicity with lidocaine which was controlled in our study by dose and image guidance, review of literature did not indicate significant soft tissue injury with lidocaine unlike other neurolytic agents such as phenol and alcohol. Two case reports have been published in the ophthalmology literature with cases of ptosis and diplopia after lidocaine injection for retro-orbital nerve blocks causing what is presumed to be due to ocular muscle necrosis, but not proven by biopsy (63-64). Kim et al (38) in their canine sciatic nerve study reported no gross changes seen in surrounding soft tissue. There is also theoretical concern regarding the possible spread of a neurolytic agent in close proximity to exiting spinal nerve roots. To reduce the risk of any complications due to this cause, contrast was injected with fluoroscopic imaging to ensure lack of epidural and vascular uptake with limitation of volume at each level of $1 \mathrm{~mL}$ of $10 \%$ lidocaine. The limiting of the volume of the neurolytic agent further to standard $0.5 \mathrm{~mL}$ may help prevent any unwanted spread. Only one study by Dreyfuss et al (60) addressed the potential spread of injectate toward neural structures other than the target nerve. Their study injected $0.5 \mathrm{~mL}$ contrast for MBB in both cadavers and healthy volunteers at the 
standard target site and slightly below the site and found spread toward neural structure occurred in $16 \%$ of all patients which our study did not see and such high rate of inadvertent neural blockade has not been reported in the literature. They did note one technical point that those patients who did have neural spread were injected in the traditional target area and those who did not were a slightly lower. On subsequent follow-up, they found the same patients who had neural spread did not have it on repeat block if the lower target area was used and bevel oriented down and medially. Our present study used volumes $>0.5 \mathrm{~mL}$ used in the study by Dreyfuss, which could degrade the diagnostic value of the MBB performed in our study with $\mathrm{BM}$ of $1 \mathrm{~mL}$ and $10 \%$ lidocaine median volume of $7.5 \mathrm{~mL}$. Neither groups, however, reported clinical evidence of epidural spread. Since both groups received $>0.5 \mathrm{~mL}$ of volume, this may be less of a confounding factor.

\section{CONCLUSION}

Higher concentrations (10\%) of lidocaine appears to be an moderately effective neurolytic agent in lumbar medial branch blocks for chronic low back pain due to lumbar facet arthopathy. The nerve blocks with $10 \%$ lidocaine increased he duration of pain relief from MBB when compared with $0.5 \%$ BM without complication. However, the duration of relief was shorter in duration than literature reported response to RFTC. It may place a niche role for patients who have relief with MBB but no relief with RFTC. Ten percent lidocaine may also have a substitute role for RFTC especially for patient who have contraindications to RFTC such as pacemaker/defibrillators or RFTC cannot be performed due to technical issues placing the electrode. The study was limited in number and its retrospective nature. Further prospective study with a larger population using alternate placement of blockade needle should be performed.

\section{Acknowledgments}

All authors were involved in the collection and interpretation of data as well as preparation of this manuscript. There are no conflict of interests to disclose by the authors. Special thanks to the editorial board for their constructive suggestion. 
Prolongation of Lumbar Facet Joint Nerve Block Duration

\section{REFERENCES}

1. Hoy D, Bain C, Williams G, Marcha L, Brooks P, Blyth F, Woolf A, Vos T, Buchbinder R. A systematic review of the global prevalence of low back pain. Arthritis Rheum 2012; 64:2028-2037.

2. Itz CJ, Geurts JW, van Kleef M, Nelemans P. Clinical course of nonspecific low back pain: A systematic review of prospective cohort studies set in primary care. Eur J Pain 2013; 17:5-15.

3. Boswell MV, Manchikanti L, Kaye AD, Bakshi S, Gharibo CG, Gupta S, Jha S, Nampiaparampil DE, Simopoulos TT, Hirsch JA. A best-evidence systematic appraisal of the diagnostic accuracy and utility of facet (zygapophysial) joint injections in chronic spinal pain. Pain Physician 2015; 18:E497-E533.

4. Manchikanti L, Kaye AD, Boswell MV, Bakshi S, Gharibo CG, Grami V, Grider JS, Gupta S, Jha S, Mann DP, Nampiaparampi DE, Sharma CC, Shroyer LN, Singh V, Soin A, Vallejo R, Wargo BW, Hirsch JA. A systematic review and best evidence synthesis of the effectiveness of therapeutic facet joint interventions in managing chronic spinal pain. Pain Physician 2015; 18:E535E582.

5. Manchikanti L, Hirsch JA, Falco FJ, Boswell MV. Management of lumbar zygapophysial (facet) joint pain. World J Orthop 2016; 7:315-337.

6. Marks RC. Distribution of pain provoked from lumbar facet joints and related structures during diagnostic spinal infiltration. Pain 1989; 39:37-40.

7. Fukui S, Ohseto K, Shiotani M, Ohno K, Karasawa H, Naganuma Y. Distribution of referred pain from the lumbar zygapophyseal joints and dorsal rami. Clin J Pain 1997; 13:303-307.

8. Kotsenas AL. Imaging of posterior element axial pain generators: Facet joints, pedicles, spinous processes, sacroiliac joints, and transitional segments. Radiol Clin North Am 2012; 50:705730.

9. Lee JC, Cha JG, Yoo JH, Kim HK, Kim HJ, Shin BJ. Radiographic grading of facet degeneration, is it reliable? A comparison of MR or CT grading with histologic grading in lumbar fusion candidates. Spine ] 2012; 12:507-514.

10. Van Rijn RM, Wassenaar M, Verhagen AP, Ostelo RW, Ginai AZ, de Boer MR, van Tulder MW, Koes BW. Computed tomography for the diagnosis of lumbar spinal pathology in adult patients with low back pain or sciatica: A diagnostic systematic review. Eur Spine ] 2012; 21:228-239.

11. Koh WU, Kim SH, Hwang BY, Choi WJ, Song JG, Suh JH, Leem JG, Shin JW. Value of bone scintigraphy and single photon emission computed tomography (SPECT) in lumbar facet disease and prediction of short-term outcome of ultrasound guided medial branch block with bone SPECT. Korean J Pain 2011; 24:81-86.

12. Jung JH, Kim HI, Shin DA, Shin DG, Lee JO, Kim HJ, Chung JH. Usefulness of pain distribution pattern assessment in decisionmaking for the patients with lumbar zygapophyseal and sacroiliac joint arthropathy. J Korean Med Sci 2007; 22:1048-1054.

13. Derby R, Melnik I, Choi J, Lee JE. Indications for repeat diagnostic medial branch nerve blocks following a failed first medial branch nerve blocks. Pain Physician 2013; 16:479-488.

14. Manchikanti L, Pampati S, Cash KA. Making sense of the accuracy of the diagnostic lumbar facet joint nerve blocks: An assessment of the implications of $50 \%$ relief, $80 \%$ relief, single block, or controlled diagnostic blocks. Pain Physician 2010; 13:133-143.

15. Manchikanti L, Pampati V, Fellows B, Bakhit CE. The diagnostic validity and therapeutic value of medial branch blocks with or without adjuvants. Curr Rev Pain 2000; 4:337-344.
16. Pampati S, Cash KA, Manchikanti L. Accuracy of diagnostic lumbar facet joint nerve blocks: A 2 year follow up of 152 patients diagnosed with controlled diagnostic blocks. Pain Physician 2009; 12:855-866.

17. Gallager J, Vadi PLP, Wesley JR. Radiofrequency facet joint denervation in the treatment of low back pain: A prospective controlled double-blind study in assess to efficacy. Pain Clinic 1994; 7:193-198.

18. Van Kleef M, Barendse GA, Kessels F, Voetts HM, Weber WE, de Lange S. Randomized trial of radiofrequency lumbar facet denervation for chronic low back pain. Spine 1999; 24:19371942.

19. Leclaire R, Fortin L, Lambert R, Bergeron YM, Rossignol M. Radiofrequency facet joint denervation in the treatment of low back pain: A placebo-controlled clinical trial to assess efficacy. Spine 2001; 26:1411-1416.

20. van Wijk RM, Geurts JW, Wynne HJ, Hammink E, Buskens E, Lousberg, Knape JT, Groen GJ. Radiofrequency denervation of lumbar facet joints in the treatment of chronic low back pain: A randomized, double-blind, sham lesion-controlled trial. Clin J Pain 2005; 21:335-344.

21. Johansson A, Hao J, Sjolund B. Local corticosteroid application blocks transmission in normal nociceptive C-fibres. Acta Anaesthesiol Scand 1990; 34:335-338.

22. Hashimoto K, Sakura S, Bollen AW, Ciriales R, Drasner K. Comparative toxicity of glucose and lidocaine administered intrathecally in the rat. Reg Anesth Pain Med 1998; 23:444-450.

23. Kalichman MW, Moorhouse DF, Powell HC, Myers RR. Relative neural toxicity of local anesthetics. J Neuropath Exp Neur 1993; 52:234-240.

24. Kanai $Y$, Katsuki H, Takasaki M. Graded, irreversible changes in crayfish giant axon as manifestations of lidocaine neurotoxicity. Anesth Analg 1998; 86:569-573.

25. Ready LB, Plumer MH, Haschke RH, Austin E, Sumi SM. Neurotoxicity of intrathecal local anesthetics in rabbits. Anesthesiology 1985; 63:364-370.

26. Lambert LA, Lambert DH, Strichartz GR. Irreversible conduction block in isolated nerve by high concentrations of local anesthetics. Anesthesiology 1994; 80:1082-1093.

27. Bainton CR, Strichartz GR. Concentration dependence of lidocaine -induced irreversible conduction loss in frog nerve. Anesthesiology 1994; 81:657-667.

28. Lirk P, Flatz M, Haller I, Hausott B, Blumenthal S, Stevens MF, Suzuki S, Klimaschewski L, Gerner P. In Zuker diabetic fatty rats, subclinical diabetic neuropathy increases in vivo lidocaine. Reg Anesth Pain Med 2012; 37:601-606.

29. Farber SJ, Saheb-Al-Zamani M, Zieske L, Laurido-Soto O, Bery A, Hunter D, Johnson P, Mackinnon SE. Peripheral nerve injury after local anesthetic injection. Anesth Analg 2013; 117:731-739.

30. Yang S, Abrahams MS, Hurn PD, Grafe MR, Kirsch J. Local anesthetic Schwann cell toxicity is time and concentration dependent. Reg Anesth Pain Med 2011; 36:444-451.

31. Perez-Castro R, Patel S, Garavito-Aguilar ZV, Rosenberg A, Recio-Pinto E, Zhang J, Blanck TJJ, Xu F. Cytotoxicity of local anesthetics in human neuronal cells. Anesth Analg 2009; 108:9971007.

32. Myers RR, Heckman HM. Effects of local anesthetics on nerve blood flow: Studies using lidocaine with and without epinephrine. Anesthesiology 1989; 71:757-762.

33. Johnson ME. Uhl CB. Toxic elevation of cytoplasmic calcium by 
high lidocaine in a neuronal cell line. Reg Anesth 1997; 22:A68.

34. Johnson ME, Uhl CB. Saenz JA, DaSilva AD. Lidocaine is more neurotoxic than bupivacaine, with a different mechanism of cytoplasmic calcium elevation. Reg Anesth 1998; 23:A30.

35. Choi YK, Liu J. The Use of $5 \%$ lidocaine for prolonged analgesia in chronic pain patients: A new technique. Reg Anesth Pain Med 1998; 23:96-100.

36. Hempl KF, Schneider, Thorin D, Ummenhofer W, Drewe J. Hyperosmolarity does not contribute to transient radicular irritation after spinal anesthesia with hyperbaric $5 \%$ lidocaine. Reg Anesth 1995; 20:363-368.

37. Keld DB, Hein L, Dalgaard M, Krogh L, Rodt SÅ. The incidence of transient neurologic symptoms (TNS) after spinal anaesthesia in patients undergoing surgery in the supine position. Hyperbaric lidocaine $5 \%$ versus hyperbaric bupivacaine $0.5 \%$. Acta Anaesthesiol Scand 2000; 44:285-290.

38. Kim DD, Asif A, Kataria S. Presentation of neurolytic effect of $10 \%$ lidocaine after perineural ultrasound guided injection of a canine sciatic nerve: A pilot study. Korean J Pain 2016; 29:158163.

39. Kim DD, Sibai N. Prolongation of greater occipital neural blockade with $10 \%$ lidocaine neurolysis: A case series of a new technique. J Pain Res 2016; 9:721-725.

40. Han KR, Kim C, Chae YJ, Kim DW. Efficacy and safety of high concentration lidocaine for trigeminal nerve block in patients with trigeminal neuralgia. Int J Clin Pract 2008; 62:248-254.

41. Lee JW. The use of $10 \%$ lidocaine for prolonged analgesia in neuropathic patients: 207. Reg Anesth Pain Med 2003; 28:35.

42. Rocha ID, Cristante AF, Marcon RM, Oliveira RP, Letaif $O B$, Barros Filho TE. Controlled medial branch anesthetic block in the diagnosis of chronic lumbar facet joint pain: The value of a three-month follow-up. Clinics (Sao Paulo, Brazil) 2014; 69:529534.

43. Arner S, Lindblom U, Meyerson BA, Molander C. Prolonged relief of neuralgia after local anesthetic block. A call for further experimental and systematic clinical studies. Pain 1990; 43:287297.

44. Lavoie PA, Khazen T, Filion PR. Mechanisms of the inhibition of fast axonal transport by local anesthetics. Neuro-pharmacology 1989; 28:175-181.

45. Bisby MA. Inhibition of axonal transport in nerves chronically treated with local anesthetics. Exp Neurol 1975; 47:481-489.

46. Katz WA, Rothenberg R. Section 3:The nature of pain: Pathophysiology. J Clin Rheumatol 2005; 11:S11-S15.

47. Melzack R, Coderre TJ, Katz J, Vaccarino AL. Central neuroplasticity and pathological pain. Ann N Y Acad Sci 2001; 933:157174.

48. Cassuto J, Sinclair R, Bonderovic M. Anti-inflammatory properties of local anesthetics and their present and potential clinical implications. Acta Anaesthesiol Scand 2006; 50:265-282.

49. Zell V, Juif PE, Hanesch U, Poisbeau P, Anton F, Darbon P. Corticosteroid analgesia is mediated by the spinal production of neuroactive metabolites that enhance GABAergic inhibitory transmission on dorsal horn rat neurons. Eur J Neurosci 2015;
41:390-397

50. Manchikanti L, Pampati V, Bakhit CE, Rivera JJ, Beyer CD, Damron KS, Barnhill RC. Effectiveness of lumbar facet joint nerve blocks in chronic lower back pain: A randomized clinical trial. Pain Physician 2001; 4:101-117.

51. Manchikanti L, Pampati V, Fellows B, Baha GA. The inability of the clinical picture to characterize pain from facet joints. Pain Physician 2000; 3:158-166.

52. Schwarzer AC, Aprill C, Derby R, Fortin J, Kine G, Bogduk N. Clinical features of patients with pain stemming from the lumbar zygapophysial joints. Is the lumbar facet syndrome a clinical entity? Spine 1994; 10:1132-1137.

53. Schwarzer AC, Aprill CN, Derby R, Fortin J, Kine G, Bogduk N. The false-positive rate of uncontrolled diagnostic blocks of the lumbar zygapophysial joints. Pain 1994; 58:195-200.

54. Schütz U, Cakir B, Dreinhöfer K, Richter M, Koepp H. Diagnostic value of lumbar facet joint injection: A prospective triple cross-over study. PLoS One 2011; 6:e27991.

55. Manchikanti L, Damron KS, Rivera J, McManus C, Jackson S, Barnhill R, Martin J. Evaluation of sedation as a confounding factor in the diagnostic validity of lumbar facet joint pain: A prospective, randomized double-blind, placebo controlled evaluation. Pain Physician 2004; 7:411-417.

56. Manchikanti L, Pampati V, Damron KS, McManus CD, Jackson SD, Barnhill RC, Martin JC. The effect of sedation on diagnostic validity of facet joint nerve blocks: an evaluation to assess similarities in population with involvement in cervical and lumbar regions. Pain Physician 2006; 9:47-51.

57. Civelek E, Cansever T, Kabatas S, Kircelli A, Yilmaz C, Musluman M, Ofluoglu D, Caner H. Comparison of effectiveness of facet joint injection and radiofrequency denervation in chronic low back pain. Turk Neurosurg 2012; 22:200-206.

58. Dobrogowski J, Wrzosek A, Wordliczek J. Radiofrequency denervation with or without addition of pentoxifylline or methylprednisolone for chronic lumbar zygapophysial joint pain. Pharmacol Rep 2005; 57:475-480.

59. Son JH, Kim SD, Kim SH, Lim DJ, Park JY. The efficacy of repeated radiofrequency medial branch neurotomy for lumbar facet syndrome. J Korean Neurosurg Soc 2010; 48:240-243.

60. Dreyfuss P, Schwarzer AC, Lau P, Bogduk, N. Specificity of lumbar medial branch and $L 5$ dorsal ramus blocks. A computed tomography study. Spine 1997; 22:895-902.

61. Cosman ER, Dolensky JR, Hoffman RA. Factors that affect radiofrequency heat lesion size. Pain Med 2014; 15: 2020-2036.

62. Provenzano DA, Lassila HC, Somers D. The effect of fluid Injection on lesion size during radiofrequency treatment. Reg Anesth Pain Med 2010; 35:338-342.

63. Rainin EA, Carlson BM. Postoperative diplopia and ptosis. A clinical hypothesis based on the myotoxicity of local anesthetics. Arch Opthalmol 1985; 103:1337-1339.

64. Blum RA, Lim LT, Weir CR. Diplopia following sub-tenon's anaesthesia: An unusual complication. Int Ophthalmol 2012; 32:191-193. 